\title{
'Phantom Virtual' Penampang Melintang Buah Manggis (Garcinia mangostana L.) Berbasis Konsep Rangkaian Resistor pada Tomografi Elektrik untuk Non Destructive Imaging Buah Tropik
}

\author{
Amanatulhay Pribadi $^{1)}$, A.D. Garnadi ${ }^{2)}$, M.N. Indro ${ }^{3)}$, MT Julianto ${ }^{2)}$ \\ ${ }^{1)}$ TeknikElektro, Institut Teknologi Bandung \\ ${ }^{2)}$ Departemen Matematika, Institut Pertanian Bogor \\ ${ }^{3)}$ DepartemenFisika, Institut Pertanian Bogor
}

\begin{abstract}
ABSTRAK
Tomografi elektrik berguna untuk mencitrakan distribusi impedansi pada suatu benda. Tomografi dapat diaplikasikan ke berbagai bidang, salah satunya untuk bidang pasca panen maupun kwalitas penjaminan mutu sebagai peranti pencitraan bagian dalam buah secara utuh tanpa merusak. Buah manggis sebagai salah satu jenis buah tropis yang eksotis memiliki resistansi yang beragam bergantung pada material jaringan yang menyusunnya. Penampang buah manggis dimodelkan dalam bentuk phantom resistor model yang merepresentasikan tiga objek dengan resistansi berbeda, yaitu kulit luar, daging buah, dan biji. Dengan menggunakan boundary data simulator (BDS) berbasis rangkaian listrik dengan menggunakan pola arus tetanggan, dibangkitkan data set untuk phantom yang merepresentasikan jaringan melintang buah manggis. Data set yang dibangkitkan akan menjadi input inversi untuk memperoleh citra Non Destructive Imaging dengan menggunakan software rekonstruksi semisal EIDORS (electrical impedance tomography and diffuse optical tomography recosntrustion software), sebagai kalibrasi rekonstruksi.
\end{abstract}

Kata Kunci : Manggis, EIT, BDS, Non Destruktif, EIDORS

\section{PENDAHULUAN}

Pencitraan jaringan dalam buah yang tidak invasive dibutuhkan untuk menghindari resiko pembelahan/pengupasan buah. Salah satu metode yang dapat digunakan adalah electrical impedance tomography (EIT) yang mencitrakan distribusi impedansi sebuah benda. EIT bekerja dengan mengukur tegangan pada boundary lalu menggunakannya untuk merekonstruksi citra impedansi. 
Untuk mengkaji kinerja algoritma inversi EIT, dikembangkan benda uji (phantom) yang merepresentasikan objek yang kita inginkan yaitu pada kebutuhan kali ini adalah buah manggis. Buah manggis sebagai benda biomaterial memiliki resistansi yang beragam bergantung pada komponen penyusunnya. Dengan menggunakan boundary data simulator (BDS) berbasis rangkaian listrik dengan menggunakan pola arus tetanggaan, dapat dibangkitkan data set untuk phantom yang merepresentasikan jaringan melintang buah manggis. Rika Putri [10] mempublikasikan data resistivitas setiap komponen buah manggis.

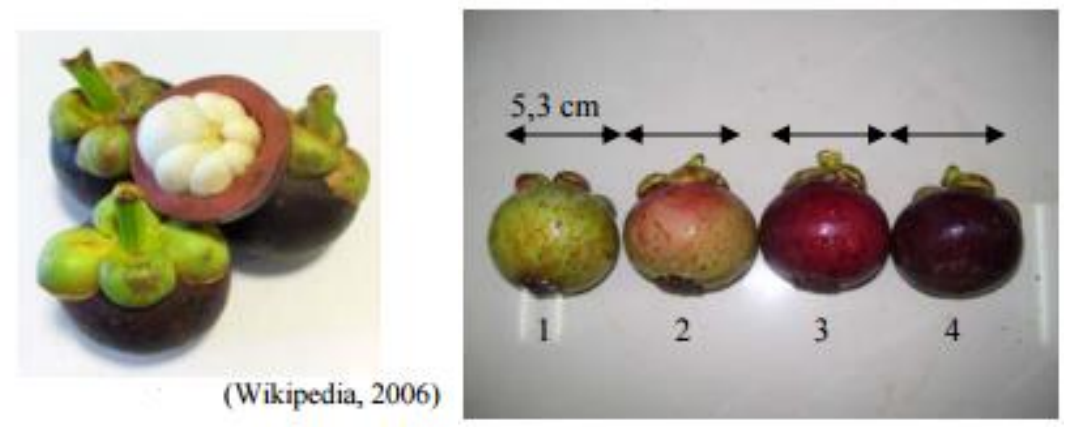

Gambar1 a. Buah Manggis. b. Buah Manggis dengan berbagai tingkat kematangan. [10]

Penampang buah manggis dapat disederhanakan menjadi sebuah phantom model tersusun dari rangkaian resistor yang terdiri dari tiga objek dengan resistansi berbeda, yaitu:

- Kulit buah (resistansi $3076 \Omega$ )

- $\quad$ Daging buah (resistansi $13333 \Omega$ )

- $\quad$ Biji (resistansi $1904 \Omega$ )

Untuk penelitian kali ini, digunakan pendekatan nilai komponen buah manggis sebagaimana ditampilkan pada tabel di bawah ini.

Tabel 1. Referensi nilai resistansi spesifik komponen buah manggis dituliskan [10]

\begin{tabular}{|l|c|c|}
\hline \multicolumn{1}{|c|}{ Material } & Specific conductance $(\mu \mathrm{S})[10]$ & $\mathrm{R}$ (resistansi) $=1 / \mathrm{G}(\mathrm{Ohm} \mathrm{cm})$ \\
\hline Kulit buah & $200-450$ & $1 / 450-1 / 200$ \\
\hline Daging buah & $50-100$ & $1 / 100-1 / 50$ \\
\hline Biji & $475-625$ & $1 / 625-1 / 475$ \\
\hline
\end{tabular}

Rentang nilai konduktansi buah adalah

- Kulit dipilih $325 \mu \mathrm{S}$

- Daging dipilih $75 \mu \mathrm{S}$

- Biji dipilih $525 \mu \mathrm{S}$

- Kulit $=1 / 325(1 / \mu \mathrm{S})=3076,923 \sim 3076 \Omega$

- $\quad$ Daging $=1 / 75(1 / \mu S)=13.333,333 \sim 13333 \Omega$

- Biji $=1 / 525(1 / \mu \mathrm{S})=1904,7619 \sim 1904 \Omega$ 


\section{METODE PENELITIAN}

1. Model continuum dan diskretisasi metode finite element

Jun Gu dalam papernya [6] memodelkan Electrical Resistance Tomography (ERT) sebagai model resistor diskrit dengan menggunakan metode FE (finite element). Persamaan yang mengatur medan arus pada sensor ERT secara umum adalah persamaan Poisson:

$$
\nabla \cdot[\sigma(x, y) \nabla \phi(x, y)]=0
$$

dengan, $\sigma(x, y)$ adalah konduktivitas dua dimensi dan $\phi(x, y)$ adalah distribusi potensial elektrik.

Kondisi batas diberikan sebagai berikut (1b-1d):

$$
\begin{gathered}
\int_{\Gamma 1} \sigma \frac{\partial \phi}{\partial n} d s=I, \int_{\Gamma 2} \sigma \frac{\partial \phi}{\partial n} d s=-I, \\
\left.\left(\varphi+z \sigma \frac{\partial \varphi}{\partial n}\right)\right|_{\Gamma_{l}}=\boldsymbol{V}_{l} \quad(l=1,2, \ldots N), \\
\left.\frac{\partial \phi}{\partial n}\right|_{\Pi}=0
\end{gathered}
$$

dengan, $\Gamma_{1}$ dan $\Gamma_{2}$, adalah domain-domain elektroda untuk injeksi arus, $\Gamma_{l}$ adalah domaindomain elektroda untuk pengukuran tegangan, Пmerepresentasikan domain-domain lain padabatas eksternal sensor, dan z menyatakan impedansi pada elektroda. Persamaan (1c) menyatakan adanya efeki mpedansi kontak elektroda sebagaimana ditunjukkan oleh Hua $\mathrm{dkk}[7]$

Finite element model yang sesuai dengan persamaan (1) adalah:

$$
K^{0} \phi=B
$$

dengan $K^{0}$ adalah matriks koefisien, $\phi$ adalah potensial elektrik pada seluruh node dan B meliputi kondisi batas.

Entri untuk $K^{0}$ dapat dinyatakan sebagai:

$$
K_{i, j}^{0}=\sum_{e=E^{0}} K_{i, j}^{e}
$$

dengan $K_{i, j}^{0}$ adalah konduktansi antara node $\mathrm{I}$ dan node $\mathrm{j}$ untuk element $e$, yang mana merupakan fungsi dari konduktivitas elemen dan geometri elemen dan $E^{0}$ adalah set elemen. 


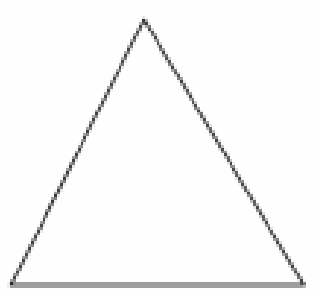

(a)

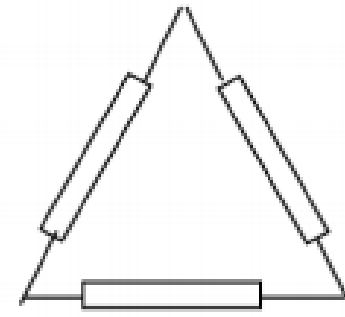

(b)

Gambar2. (a) elemen triangular pada FEM; (b) equivalent resistor network untukelemenpada (a)

Untuk elemen-elemen triangular, dengan menganalisis entri pada (3), dapat disimpulkan bahwa resistor network yang ekuivalen untuk elemen adalah dengan tiga resistor seperti yang ditunjukkan Gambar 2. Nilai resistor dapat diturunkan dari persamaan (3).

2. Virtual discrete phantom

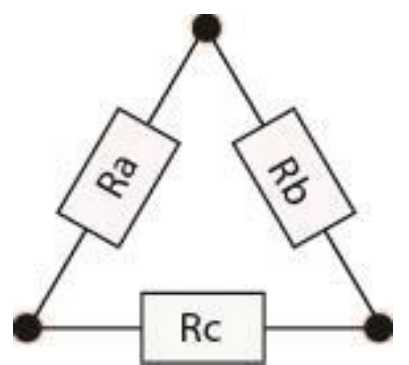

Gambar3. Segitiga resistive building block

Gambar 3 mengilustrasikan segitiga building block sebagai elemen dasar pembangun poligon resistor. Building block resistor disusun oleh tiga resistor yaitu $\mathrm{Ra}, \mathrm{Rb}$ dan $\mathrm{Rc}$. Untuk mendapatkan rangkaian polygon diperlukan proses assembly beberapa building block. Dirangkai resistor elemen segitiga yang bersisian secara parallel untuk membentuk resistor polygon seperti yang ditunjukkan oleh Gambar 4 di bawah ini. Gambar kiri memperlihatkan dua segitiga building block dengan terdapat dua resistor yang bersisian. Keduanya dapat diparalelkan menjadi satu resistor ekuivalen seperti gambar kanan. 


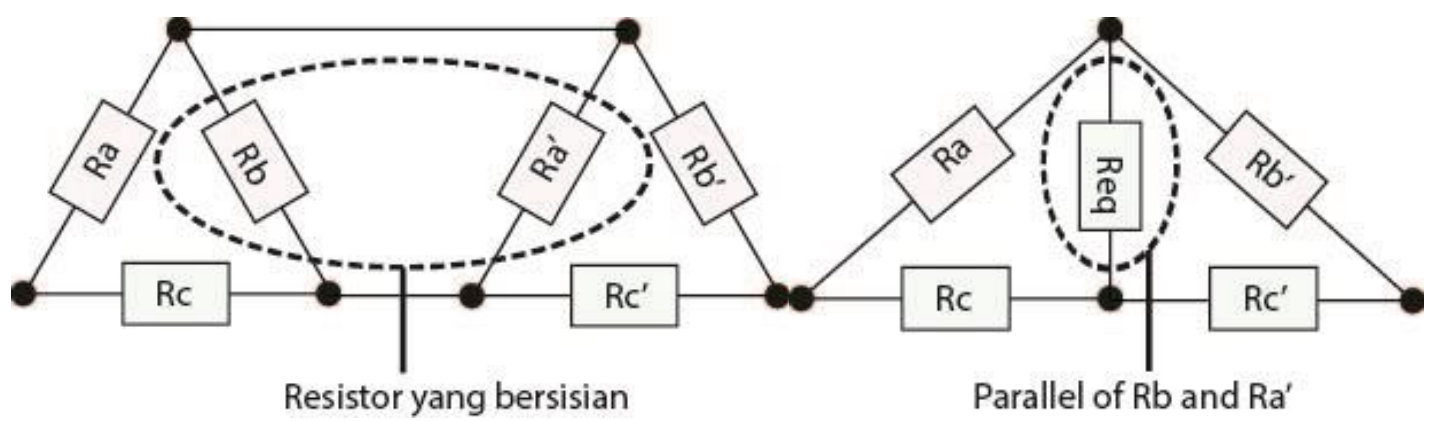

Gambar4. Proses assembly dua building blok memanfaatkan aturan penjumlahan dua resistor paralel

Proses assembly building block satu demi satu melalui proses di atas dilakukan sehingga akan diperoleh bangun resistor sebagai phantom, seperti ditunjukkan gambar di bawah ini. Perhatikan bahwa proses penjumlahan parallel hanya berlaku untuk dua building block yang bersisian, sementara resistor tepi bukan merupakan resistor ekuivalen yang dihasilkan dari penjumlahan parallel dua resistor yang berasal dari building block pembangun.

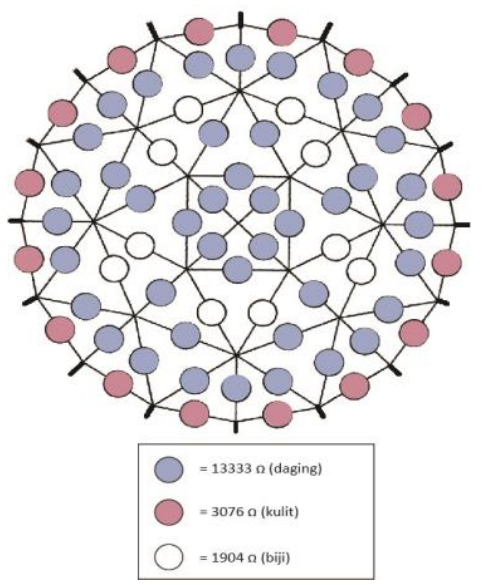

Gambar5. Rangkaian resistor phantom sebagai model penampang melintang buah manggis yang disusun berdasarkan penempatan komponen penyusunnya: biji, daging, dan kulit

Skematik rangkaian resistor di atas merupakan representasi penampang melintang buah manggis. Adapun spesifikasi yang digunakan adalah sebagai berikut:

- Jumlah resistor $\quad=68$ buah

- Jumlah elektroda $\quad=16$ buah

- Pola injeksi arus =adjacent / neighbouring

- Elektroda diposisikan pada noda tepi, sebagai tempat injeksi arus sekaligus pengukuran tegangan

- Output: Data beda potensial masing-masing pasang elektroda 


\section{A Resistive-Based BDS (Boundary Data Simulator)}

Ilustrasi rangkaian resistor yang ditunjukkan pada Gambar 2 akan diimplementasikan menggunakan WinSpice 1.05.07, yaitu sebuah perangkat lunak untuk mendesain rangkaian listrik dan melakukan simulasi rangkaian dengan elemen rangkaian dapat disusun dengan script.

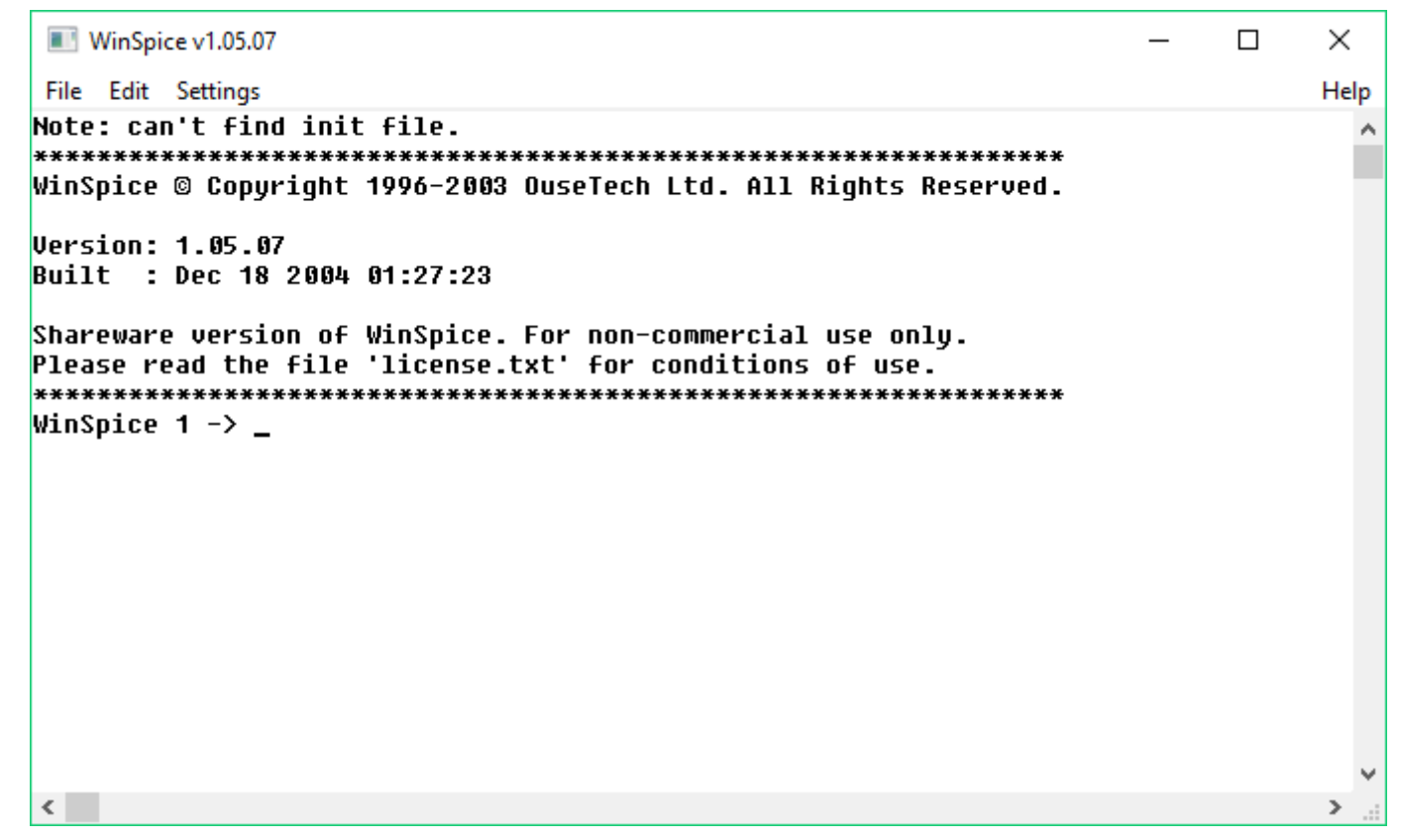

Gambar6. WinSpice v1.05.07

Winspice-based BDS ini disusun dengan script dengan 3 bagian utama yaitu rangkaian resistor sebagai virtual phantom (terdiri dari kombinasi resistor 1904 Ohm, 3076 Ohm, dan 13,333 kOhm), sumber arus dengan sepasang node sebagai posisi injeksi arus (arus AC $1 \mathrm{~mA} 50 \mathrm{kHz}$ ), dan pengukuran tegangan pada elektroda tepi. Simulasi dilakukan tiga kali yaitu untuk satu pola rangkaian homogen dan dua pola non-homogen (representasi biji buah manggis dan modifikasi).

\section{HASIL DAN PEMBAHASAN}

Tabel2. Hasil percobaan

\begin{tabular}{|l|l|l|} 
Rangkaian & Data boundary yang dihasilkanWinSpice & HasilRekonstruksi EIDORS \\
\hline
\end{tabular}




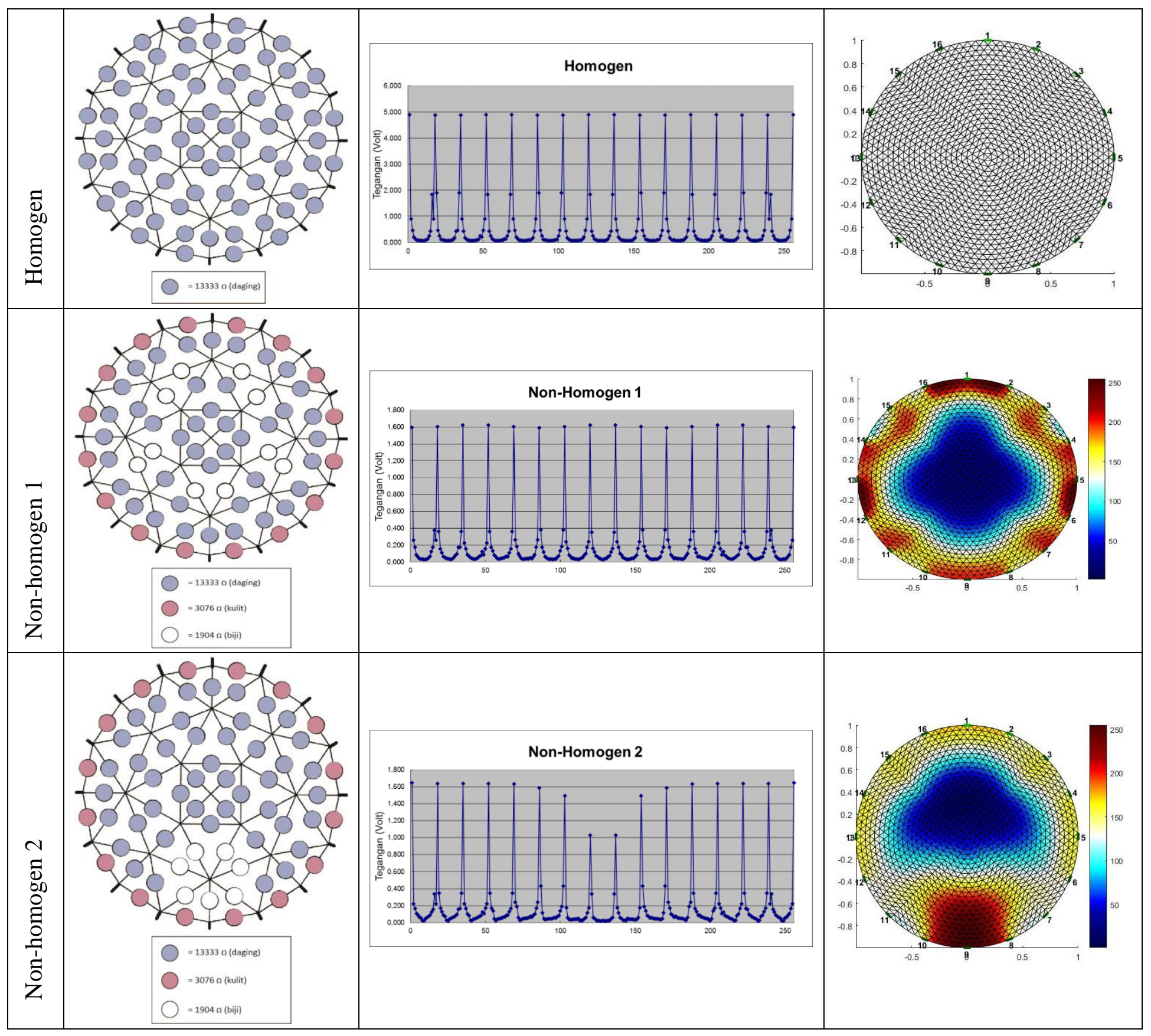

Winspice-based BDS menghasilkan data boundary masing-masing objek. Nilai tegangan maksimum pada simulasi non homogen (1,646 V dan 1,624 V) lebih rendah dari pada nilai tegangan maksimum pada simulasi homogen $(4,897 \mathrm{~V})$. Hal ini dikarenakan objek homogen seluruhnya terdiri dari daging yang berresistensi jauh lebih tinggi (13,3 kOhm) dibandingkan objek non homogen yang selain daging juga terdiri dari kulit dan biji yang resistansinya lebih rendah (3076 dan 1904 Ohm). Karena itu, total resistansi objek homogennya lebih tinggi, yang menyebabkan tegangan boundary pun lebih tinggi pula. Selain itu, puncak tegangan pada pola homogen cenderung bernilai sama (merata) sedangkan 
untuk pola penampang non homogen berbeda. Pada pola non homogen pertama di mana biji tersebar di tengah, walaupun tidak terlalu bernilai sama, namun puncaknya lebih merata. Sedangkan pada non homogen kedua di mana biji hanya terletak di satu sisi dan bersentuhan dengan pinggiran kulit, puncak tegangan boundary tidak beraturan. Puncak untuk masingmasing pola secara berurutan akan menurun di mana titik puncak terendah adalah saat titik injeksi arus berdekatan dengan resistansi rendah (biji).

Data boundary yang dikumpulkan dapat digunakan untuk rekonstruksi citra dengan EIDORS (Electrical Impedance and Diffuse Optical Tomography Reconstruction Software). Rekonstruksi dilakukan dengan metode difference yaitu perbedaan data homogeny dengan data yang diukur (non homogen). Terlihat adanya gradasi warna yang berlekuk-lekuk mengikuti sebaran biji.

Terlihat pula pada hasil simulasi non homogen kedua bahwa region citra yang merepresentasikan daging terlihat kontras dengan warna biru, sedangkan biji walaupun luasnya kecil namun terbedakan sebagai corak merah. Sedangkan untuk hasil simulasi non homogen pertama, luas biji dan daging tidak dapat terlihat seperti non homogen kedua.

Winspice-based BDS ini disusun dengan script dengan 3 bagian utama yaitu rangkaian resistor sebagai virtual phantom (terdiri dari kombinasi resistor 1904 ?], 3076 ?], dan 13,333 $\mathrm{k}$ ?), sumber arus dengan sepasang node sebagai posisi injeksi arus (arus AC $1 \mathrm{~mA} 50 \mathrm{kHz}$ ), dan pengukuran tegangan pada elektroda tepi. Simulasi dilakukan 3 kali yaitu untuk pola rangkaian homogen dan dua jenis non-homogen (representasi buah).

Rekonstruksi dilakukan dengan EIDORS (Electrical Impedance and Diffuse Optical Tomography Reconstruction Software) menggunakan metode difference yaitu perbedaan data homogen dengan data yang diukur (non homogen). Adapun asumsi data homogen kali ini adalah dengan resistansi daging.

\section{KESIMPULAN}

1. WinSpice-based BDS (boundary data simulator) dapat digunakan dalam pembangkitan data untuk model penampang melintang tungkai hewan. Rekonstruksi menggunakan data boundary tersebut dilakukan dengan EIDORS (Electrical Impedance and Diffuse Optical Tomography Reconstruction Software) berdasarkan perbedaan data antara data output homogen dengan nonhomogenya. 
2. Pemodelan penampang melintang buah manggis disusun menggunakan tiga elemen penyusun, berupa: biji, daging buah dan kulitnya. Ketiganya memilik iresistansi yang berbeda yang akan terlihat kontras pada rekonstruksi citra.

\section{UCAPAN TERIMA KASIH}

Penelitian ini merupakan bagian dari usulan PSU PUPT-IPB 2016, Pengembangan Teknologi Rekonstruksi Tomography ECVT Berbasis Open Source untuk Nondestructive Testing Kualitas Produk Pertanian Pasca Panen. Dibiayai oleh Direktorat Riset dan Pengabdian Masyarakat Direktorat Jenderal Penguatan Riset dan Pengembangan Kementrian Riset, Teknologi, dan Pendidikan Tinggi sesuai dengan Surat Perjanjian Penugasan Pelaksanaan Program Penelitian Nomor: 079/SP2H/LT/DRPM/II/2016.

\section{DAFTAR PUSTAKA}

1. A. R. Daniels, R. G. Green, dan I. Basarab-Horwath, Modelling of three-dimensional resistive discontinuities using HSPICE, Measurement Science and Technology 7.3338 (1996)

2. H. Gagnon, M. Cousineau, A. Adler, dan A. E. Hartinger, A resistive mesh phantom for assessing the performance of EIT systems, Biomedical Engineering, IEEE Transactions on, 57(9), 2257-2266 (2010)

3. G. Hahn, A. Just, J. Dittmar, dan G. Hellige, Systematic errors of EIT systems determined by easily-scalable resistive phantoms, Physiological measurement 29, no. 6 : S163 (2008)

4. M.A. Hussain, B. Noble, dan B. Becker, Computer Simulation of an Inverse Problem for Electric Current Computed Tomography using a Uniform Triangular Discretization, Engineering in Medicine and Biology Society, Images of the Twenty-First Century, Proceedings of the Annual International Conference of the IEEE Engineering in IEEE (1989)

5. Péter Krammer, Andreas D. Waldmann, Michel Zogg, Péter L. Róka1, Josef X. Brunner, dan Stephan H. Bohm, Electrical impedance tomography simulator, Proceedings EIT2015, p40 (2015)

6. Jun Gu, W Yin, YannianRui, Chao Wang, danHuaxiang Wang, A New Resistor Network Based Forward Model for Electrical Impedance Tomography Sensors, International 
Instrumentation and Measurement Technology Conference, Singapore, 5-7 May 2009 (2009)

7. P. Hua, E. J. Woo, J. G. Webster, dan W. J. Tompkins, Finite element modeling of electrode-skin contact impedance in electrical impedance tomography, IEEE Transactions on Biomedical Engineering, 40(4), 335-343 (1993)

8. M. H. Padmanaba, F. Ardhy, I. Hariadi, H. Zakaria. Development of Laboratory-Scale Electrical Impedance Tomography Imaging System, 2015 4th International Conference on Instrumentation, Communications, Information Technology, and Biomedical Engineering (ICICI-BME) (2015)

9. B.W. Watson (Ed.), IEE Medical Electronics Monographs 1-6

10. Rika Putri, Kajian Sifat Listrik Buah Manggis (Garcinia mangostana L.) Pada Tingkat Kematangan Berbeda, Skripsi, Dept. Fisika, IPB, 2007 